\title{
The 'C-Word': Novice teachers, class identities and class strategising
}

\author{
By
}

Lisa Jones

The University of Hull

Correspondence details:

Email: $\quad$ l.m.jones@hull.ac.uk

Postal address: $\quad$ School of Education and Social Sciences

Faculty of Arts, Culture and Education

University of Hull

Cottingham Road

Kingston Upon Hull

HU6 7RX

Tel: +44 (0)1482 462052

Total word count including reference list (excluding abstract/key words/title): 9,014

This is an Accepted Manuscript of an article published by Taylor \& Francis in Pedagogy, Culture and Society on 14 Jan 2019, available online:

https://www.tandfonline.com/doi/full/10.1080/14681366.2019.1566161. 


\title{
The 'C-Word': Novice teachers, class identities and class strategising
}

\begin{abstract}
This paper draws on a longitudinal qualitative study exploring the influence of the social class identities of novice teachers on their emerging teacher identities. The paper focuses on the ways in which even at an implicit level, many novice teachers appear to recognise that their own (or perceptions of their own) class identity and the associated cultural capital that they bring might not be equally valued in all school settings. Thus, whilst some novice teachers are constrained/restricted by their class identities, others, often those with middle-class identities, are more able to play strategically with their class, minimising the potential disadvantages of a perceived lack of appropriate cultural capital. This paper therefore sets out to explore these responses given they yield strong support for the self-reflection, problematisation and critique of novice teachers’ identities in initial teacher education and training programmes.
\end{abstract}

\section{Keywords}

Novice teachers; pre-service teachers; social class identity; class strategising; cultural capital; teacher education 


\section{Introduction}

Social class has largely been met with silence and resistance within both policy and wider discourses around Initial Teacher Education (ITE) (Reay 2006; Burn and Childs 2016) despite the overwhelming evidence of its central role in relation to educational inequalities (Reay 2017; Leathwood and Archer 2006). This paper explores how the class background and identities of novice teachers influence their early professional and pedagogical choices as they become teachers. Drawing upon cultural analyses of class, this paper aims to highlight the ways in which novice teachers may be seen to be drawing upon particular forms of strategising in relation to their own (and perceptions of their own) social class identities. This surfaces due to an often implicit sense that the associated cultural capital that they bring might not be equally valued in all school settings. Despite the apparent influence this has on the types of schools novice teachers (the term used in the paper to denote both the pre-service 'training' period and the probationary/newly qualified teaching year) apply to and feel able to become teachers in, little is understood about the way in which this works and it remains an under-explored area.

\section{Cultural analyses of class}

Social class is a powerful albeit contested concept to understand and analyse social and economic inequalities and resulting social divisions and hierarchies in inherently unequal societies (Reay 2006). Here, class is generally understood as a relational concept where classes only exist in relation to other classes of people, separated on the basis of differential levels of access to power and resources/capital that extend beyond purely economic or occupational divisions (Savage et al. 2015). 
The debates about social class, its meaning and resonance in complex, vastly changing global societies are well documented and ongoing. In particular, the 1980s and 1990s were characterised by a discourse surrounding the 'death of class’ (Pakulski and Waters 1996) whereby the usefulness of the concept was critiqued by a number of seminal texts as deterministic and unfit to capture the complexities of the modern world (Bauman 1982; Lash and Urry 1987; Beck 1992). However, the closing stages of the twentieth century and the beginning of the new millennium signalled what Savage (2003) heralded a 'new class paradigm' where understandings of class shifted from underpinning questions about 'who fits where?', to exploring the importance of class-based identities, attitudes and social practices in understanding how inequalities are powerfully reproduced (Devine 1997; Skeggs 1997).

This ‘cultural turn’ (Crompton 2008; Evans 2017), drawing heavily on the work of Pierre Bourdieu, offered the opportunity to explore an education policy context of increasing marketisation in schooling in the UK and other Western countries, particularly how issues of educational advantage and disadvantage were reinforced and reproduced through middle-class parenting practices and strategies (Ball 2003; Reay and Lucey, 2004; Vincent et al. 2012). Importantly, these scholarly works moved away from notions of class consciousness and resulting collective action as central in the reproduction of class inequalities in education. Instead, the focus shifted towards the way in which the strategic and reflexive orientation of middle-class practices and cultures enables them to exercise 'rational mechanisms' in an apparently ‘open’ educational market place thus helping to 'hide’ and make class inequalities less visible (Savage 2003). Here, education policy normalises middle-class values that then influence classroom practice in ways that help the reproduction of class inequalities. This may 
manifest itself through low expectations of working-class children (Stahl 2015) and demonised views of their parents and communities when teachers unquestioningly accept policy expectations that working-class parents should behave just like middle-class ones (Gewirtz 2001). It may also be seen in the way in which young people themselves construct and pathologise the working-class 'other' including how this plays out in the classroom (Hollingworth and Williams 2009).

Whilst no longer 'new', this approach to class focusing on cultural analyses, identities and practices remains a powerful framework through which to explore educational inequalities. Thus the key literatures theorising and applying this new cultural approach (published circa 1997 2009) are still drawn upon here in this paper, elsewhere more broadly and especially in educational research (see Roseneil and Frosh 2012; Evans 2017 for instance). However, one area where this theoretical framework has been under-utilised internationally is in the context of teacher education (Reay 2006).

Moreover, whilst novice teachers might explore issues around social class (alongside race and gender) in teacher education/training in both the UK and other structurally unequal Western countries, this is mostly under the guise of understanding learner identities where the focus rarely shifts towards how teachers' own identities are shaped by these factors (Allard and Santoro 2006; Santoro 2009). Arguably, both existing and novice teachers have little understanding of their own class identities that are often so deeply embedded they are rarely even visible, never mind questioned or problematised (Ladson-Billings 2001; Van Galen 2010). As such, they are likely to be 'unaware of the effects of their own classed identities on their professional practice' 
(Gazeley and Dunne 2007, 413) with little understanding of the ways in which the education system they have entered is inequitable on the grounds of class. This has led to a strong sense that where 'class' is discussed, this is often expressed via discourses that rely on deficit stereotypes locating the 'problems' of schooling to be working-class students' home lives, values and culture (Dunne and Gazeley 2008; Gorski 2012, 2016; Stahl, 2015).

The purpose of this paper then is to foreground novice teachers' class identities, drawing upon a longitudinal study of English novice teachers, as they attempted to negotiate the perceived class boundaries they encountered/anticipated encountering as they began their journeys to becoming teachers in the non-neutral classed landscape of schooling in England. The issues pertaining to middle-class novice teachers and how class is seemingly rendered invisible have been explored in depth elsewhere (Hall and Jones 2013). This paper seeks to specifically examine the forms of strategising invoked by novice teachers aligned to middle and working-class identities when they (often implicitly) understood that the cultural capital they brought into teaching may not be equally valued in all educational settings.

Importantly, classed identities may be seen as troubling, at least to some extent, for all novice teachers when it closes off certain teaching contexts in particular social environments and may result in the relative advantaging and disadvantaging of some novice teachers with regard to 'choice' of educational settings for future employment opportunities. This should be regarded as a real concern within a teacher education system whereby individuals enter into the process of becoming teachers with pre-existing views that might well be deficit in nature and potentially damaging to young people within schools. These views are likely to be resistant to change and 
with few opportunities in ITE for these views to be disrupted and challenged, this is of real concern. The paper therefore concludes by considering the implications for teacher education.

\section{Social class and class identities}

Working with any conceptualisation/s of social class is complex and as such 'ambiguity' has been argued to be a central feature of empirical studies using class (Savage, Bagnall, and Longhurst 2001). Reay’s (2006, 290) argument that social class is ‘everywhere and nowhere, denied yet continually enacted' is a reminder of the salience and persistence of class. Therefore employing any conceptualisations of social class in research opens up its users to critique because we are all implicated in any discussion of the class system in less than neutral ways (Bottero 2014). Nevertheless, it is important not to shy away from social class given the powerful lens it offers to explore often deeply hidden issues of educational advantage and disadvantage.

Savage, Bagnall, and Longhurst $(2001,889)$ powerfully argued that whilst class identities in England might generally be seen as weak and ambivalent, this should not be regarded as contradictory to the salience of the concept of class because it is '... not an innocent descriptive term but is a loaded moral signifier'. With relational notions of inferiority/superiority strongly implicated in both identification and non-identification with any class labels, 'defensiveness' about class and an attempt to present oneself as 'normal' and/or 'ordinary' (which may be middle class, working class, or even 'classless' dependent on context), is arguably a rational response, a 'strategy' even, and is demonstrative of the inherent complexities of class identities (Payne and Grew 2005). 
Due to this lack of neutrality when discussing class, self-identification with class labels is only one aspect of a class identity, and as such, individuals might helpfully be thought of as identifying with class in terms of their ' ...economic, social and discursive relations...' (Skeggs 1997, 165) not just their subjectivity (Kirk 2002). Furthermore, Payne and Grew $(2005,894)$ remind us that the general public may approach class with a 'different frame of reference from sociologists' given that they lack 'intellectually rigorous training in sociological class analysis'. They stress that many people talk about class without ever mentioning the 'c-word' directly, suggesting that it may actually be what is being discussed through the use of various terms relating to income, occupation, inequalities, attitudes, housing, educational qualifications, lifestyles and aspirations.

Bourdieu's (1986) argument that 'culture' has a particular meaning in that it is viewed as an asset or 'capital' has been particularly helpful internationally in further understanding how class-based inequalities might be routinely reproduced especially within education. In most societies, the culture that is valorised and worth more, particularly in westernised societies, is generally the culture/s associated with the more powerful social classes (Bennett et al. 2009). Thus 'capital', in all its forms (economic, cultural, social and symbolic), can be seen as the currency through which people are able to occupy and maintain their social positions and status in the social hierarchy and highlights how individuals and groups may actively both exercise and resist domination in society (Bourdieu 1986).

Building upon this, Skeggs $(1997,94)$ suggests that identities (including classed identities) are '...continually reproduced as a response to social positions through access to representational 
systems and in the conversion of forms of capital'. In Bourdieu's view, the greater the access to and possession of the different types of capital an individual has, the more likely they are to be part of or closer to the dominant group/s in society. Thus cultural capital helps to produce and reproduce class because having access to high levels of cultural capital makes access to other forms of capital easier. Importantly, the closer one's culture and identity is to the dominant culture and identity, then the more likely they are to 'succeed' in aspects of society such as wealth accumulation, occupation, social status and importantly education (Bourdieu 1986).

In the context of education, where education policy has been argued to 'valorises middle class rather than working class cultural capital' (Reay 2006, 294), popular and policy discourses of 'classlessness' or the suggestion that class is now passé might be seen as a strategic attempt to render (middle) class advantage invisible (Ball 2003) and are therefore not as neutral as they might first appear. These are important considerations in this paper.

\section{The study}

This paper draws on findings from a longitudinal study focused upon 11 individuals as they embarked upon their journey to becoming teachers in secondary schools in England (age range 11-16/11-18). This qualitative study started as they embarked upon their full time ITE course (the Postgraduate Certificate in Education - PGCE) at a Russell Group university in England. The research followed them throughout their one year full-time course and continued with them into their first year as newly qualified teachers. As explained already, the term 'novice teachers' has therefore been used to capture this two year period. The 11 novice teachers were purposively selected based on their responses to an initial questionnaire distributed to an entire PGCE cohort 
(221 students) and their willingness to voluntarily participate further. In total, 164 completed questionnaires were returned, 108 of these volunteering for further research. The questionnaire collected biographical information (including age, gender, subject area, self-identification of social class), details about participants’ own education (including type of school attended, location, school/pupil-intake) and importantly, early intentions in teaching (on types of school/pupil-intake willing/unwilling to work in).

As the study was underpinned by a focus on class identities and inequalities within education, the 'classed' intentions around where the novice teachers wanted to teach was considered as an important starting point in selecting the sample. The 108 responses were therefore initially divided into three groups: those wanting to teach in inner city/urban/working-class schools; those explicitly stating they did not want to teach in such schools and those saying they were unsure about/did not mind where they taught. Given the focus on class identity, their responses on whether they identified as belonging to a social class (and if so, which - working, middle, upper or other - plus why they answered this question in that way) was also important in selecting participants. These responses were read in conjunction with responses to other questions that could help offer further, albeit incomplete, information on their social background, such as their postcode and the type/context of school they attended. This information, alongside the reasons for where they did/did not want to teach (elicited by open-ended questions inviting qualitative responses) was then used to select the 11 novice teachers.

The purposive sample did not set out to be representative of the cohort. It did however set out to include diversity across the sample, including those who were opting to work in similar class and 
social settings/contexts to those they had experienced themselves as well as those choosing to work in vastly differing contexts to those they had experienced first-hand. It also looked to include complexities and contradictions. The decision to select 11 novice teachers in total came from trying to capture this diversity whilst remaining realistic and manageable in terms of the planned depth, scale and timeframe of the study and allowing for possible attrition. The final sample contained six females and five males, from five different secondary subject areas with ages ranging from twenty-one to an individual in their fifties. 10 of the 11 novice teachers were white British and one was from a black British (Afro-Caribbean) background.

Semi-structured interviews were conducted with all participants over the relevant two year period. Three interviews were scheduled with each participant during the first year, their PGCE year - one near the beginning, the middle and the end of the year to coincide with the three seven-week practical teaching placements that were a mandatory aspect of the course they were studying. 10 out of the 11 novice teachers were interviewed the full three times (one was interviewed only twice due to illness), all of these interviews were on a face-to-face basis. Nine of the 11 novice teachers were then interviewed at the end of their first year as a newly qualified teacher (two lost to attrition), with eight out of these nine being phone interviews to accommodate for geographical distance. All interviews lasted between 30 and 90 minutes (averaging approximately 45 minutes). Interviews were audio-recorded with consent and fully transcribed shortly afterwards.

The data was subject to thematic analysis cross-sectionally after each 'round' of interviewing and then over time both for each participant and again cross-sectionally. The thematic analyses 
were iterative, continually both informed by and themselves informing a strong engagement with and theoretical sensitisation to the existing body of literature on class, class identities and the relationship between class and education.

Whilst this study focused on 11 novice teachers in total, this paper presents the stories of four of the participants. This allows for the depth of discussion needed to focus on the ways in which their journeys towards becoming teachers were shaped by their class identities and the resultant strategies employed to navigate and negotiate class boundaries (both real and perceived). The stories that emerged in this study invariably highlighted the way class intersects with gender and ethnicity (and other important identity features) although this paper does not directly explore these and focuses specifically on the classed aspects whilst recognising it can never be fully divorced from the complexities that arise from these intersectionalities. The cases discussed in this paper do not set out to exemplify all novice teachers (and not even all the novice teachers in this study) and thus this paper makes no claims to be generalisable. Rather, the cases presented here set out to demonstrate some of the complexities and tensions around a classed identity for novice teachers working in structurally unequal societies with school systems that exemplify these inequalities. In particular, this paper sets out to demonstrate a case as to why an engagement with novice teachers' class identity and background should importantly be foregrounded in ITE programmes given the important influence it has on the shaping and development of teacher identities. This will be explored directly in the concluding elements of this paper. 
As the wider sample was handpicked, it included both those who self-identified with class labels (three as middle class, four as working class and whose interview narratives supported these selfidentifications) as well as four who did not but who then identified themselves as belonging to social classes via their ' ...economic, social and discursive relations...' (Skeggs 1997, 165), positioning themselves and others (including children, schools and communities) as belonging to some classes whilst positioning others across a strong sense of class boundaries. Three of the novice teachers featured in this paper (Clare, Simon and Matt) were from this latter group and did not initially self-identify as belonging to a social class.

Thus the cases presented in detail here have been selected to emphasise how novice teachers respond when they perceive that own class identities and the associated cultural capital they bring may be seen an 'asset' in some contexts whereas in others may be seen as a disadvantage. Importantly, the paper first considers how some novice teachers are seemingly restricted by their identities before moving on to discuss how others handle their identities in more strategic ways so as to avoid the potentially constricting elements of their own identities. All names used in the paper are pseudonyms.

\section{Restrictive (working-class) identities}

Kelly, who is white and aged 23 at the start of the research, had a strong self-identification as working class. When asked why, she responded: 
Because I do [laughs] .... it is what I am and it's working class and I think people say that social classes don't exist or affect people's opinion but I think they do, and they definitely still do exist...

Whilst Clare, also white and aged 30 at the start of the research did not initially self-identify as being working class on the questionnaire citing 'I don't really like the class thing', she did go on to discursively position herself along class lines:

...you can see it's there and everybody generalises, you know people that live in that area are posh and people who live in that area are rough because it's a council estate... My mum is very middle class-minded. She was brought up on a council estate but she couldn't wait to escape and she saw herself as better than that. Whereas I choose, I bought my own house, but it's on the end of a council estate. I've no problems, my kids play with the kids from the estate and they equally play with the kids that live in the posh private houses that live down the road ...I mean we never had any more money it was just the area we lived in, I mean my mum was actually quite poor because she'd been through a divorce so if anything, I had probably less than they did [laughs]... I don’t really know where I fit really because I was brought up with people that were definitely working class and I was never any different to them...

Both Kelly and Clare strongly linked their initial views about teaching to their own classed educational experiences, both articulating that they wanted to teach in schools not dissimilar to those they attended themselves. They also both identified that they did not want to work in 
school contexts considered to be vastly different to those they had experienced first-hand, both stating that they did not want a selective and/or fee-paying school. Kelly added that she felt she would not 'fit in' due to her 'social class and place of birth' and was not interested in: 'the pressure to get people through exams' but rather: 'helping people morally and socially in more difficult schools'. When asked why they wanted to teach where they did, they had the following to say:

There was a maths teacher, the class was really difficult and a few of the boys in there have now been in jail because I still live in that area and so I know what they've grown up into, and they responded really well to her... whereas in other lessons, you could see it was basically come in the classroom, try to get it over with as quickly as possible and then back out again and I think from seeing it from the children's point of view, how that teacher's attitude, how transparent it is, you can see whether they care or don't care within five minutes... I think I feel I could make more of a difference and get stuck in and feel like I was doing something to help them... and even if you can make slight differences to their life, probably, I know that sounds really clichéd but that's the reason why. (Kelly)

I think because I came through the system and I mean I failed it first time around totally you know, it was never really pushed and you know I think it is different now... I mean nobody I know went to university, that's how uncommon it was in the area where I am from... coming from that sort of background, if I could say to them you know what, I came from here and I did alright that hopefully it can give them a bit of incentive too... it's 
definitely the inner city kids, I think you know I think they need it more, they need to see people coming from that background... they think teachers are posh [laughs]. (Clare)

Here they both talk positively about being able to relate to the students having come from similar (working-class) backgrounds and thus having a strong sense of being able to draw on their cultural capital that would be positively valued in schools serving working-class communities. In many respects, this finding supports the work of other writers who have explored class identities whereby teachers from working-class backgrounds strongly identified with the working-class students they work with given their shared backgrounds (Maguire 2001, 2005; Burn 2001).

During the ITE year, both Clare and Kelly actively sought and had initial placements in schools closely aligned to those they had outlined they wanted to teach in (not dissimilar to their own education) with both enjoying these and enabling them to positively draw on their own experiences and the cultural capital they brought with them. However, alongside being drawn to working in familiar class settings that would enable them to empathise and act as a role model for young people like them, there was also a strong sense of fear and apprehension about going into what they perceived as a class setting vastly different to that they had experienced. Clare, for instance, said she had 'nearly cried' and talked of being 'devastated' when there was some talk during the PGCE of her going into a selective grammar school for her second placement. Here Clare reflects on this moment towards the end of her ITE year: 
...I think in some schools, I mean probably maybe I'm a bit scared too because I'm not used to them and I'd probably be like urghh, if I were sent to a private school I'd be like oh what do I do here? [laughs] and I'd probably be worried about dealing with parents and things, so I think maybe, some of it's me too... I mean the sort of parents I'm going to come across in an inner city school I know what to expect, I know how to deal with them coz they're the people I live with, the people I've been brought up with, the people who are my friends... and it's my culture really whereas if I was to go to a private school then I think maybe I'd feel that I wasn't good enough to be teaching their children coz I've not got the right accent, I’ve not got the right background...

Here, Clare explains that due to her classed experiences/identity, she only feels confident in certain classed educational settings (the inner city school), that she is familiar with and which she perceives as her 'culture'. She also stresses that she is fearful of the middle class 'Other' (the independent/ grammar schools) with a sense of feeling that she 'wasn't good enough' and did not have the 'right accent' or the 'right background'. Asked why she felt like this, she said:

It's probably a class thing, I'm not part of that class and I think I probably would have done really badly in a place like that...

Unsurprisingly perhaps given these views, Clare sought and found work in a school mirroring her own experience of schooling. In returning to Clare after her first year in teaching, she was thriving in this setting and already in the process of applying for promotion to Head of Department. In this sense, Clare was clearly able to draw positively on her own class identity as enabling her to have 
the skills, knowledge and cultural capital to 'succeed' in a familiar classed setting. However, it is difficult to ignore the strong sense that Clare's class identity potentially restricted her confidence levels to even attempt to work in class settings vastly different to those she experienced herself highlighting the potentially limiting nature of her class identity.

Unlike Clare, Kelly took up the opportunity to have a 'contrasting' placement school, albeit not in a selective or fee-paying school but one considered to be less socio-economically disadvantaged (a more socially-mixed context) and with higher levels of educational attainment than Kelly had identified wanting to work in. After initial concerns about going to Daisywood (her contrasting placement school) for fear of it being more 'academic', Kelly went on to really enjoy it, so much so, that it actually started to make her rethink her views about her ideal school type, saying: 'It was brilliant, really good, definitely the type of school I'd like to work in'. Thus, from the second interview, Kelly's concerns about choosing a place to work started to change, becoming less restricted and where 'feeling supported' to be enabled to do her job replaced her strong desire to teach children only from a similar background to her own.

After starting to look for employment, Kelly was invited for an interview for one post in a school not too dissimilar from her own schooling but Kelly did not get the job on account of being told she would: 'be suited to a more academic school'. Kelly said this had: 'really surprised me... because it was the total opposite to what everybody else had said since I've started training'. However, the week following her unsuccessful interview, Kelly was offered a post at Daisywood which she accepted. She said: 
... as soon as I started the training there, that was the one place I would love to work there because the department are really nice, supportive and friendly, and the school is a better school than I thought I'd start out in... it's got a nice mixture it's not middle to bottom it's top middle and bottom... I didn't want to be teaching in a school that was all top... so it's perfect for what I wanted to do.

On being asked whether she still wanted to teach in an inner city context longer term, she said:

...less than what did because I didn't think I'd enjoy so much teaching. It sounds strange but I didn’t think I'd enjoy as much as I do, students who are able to get top grades, I thought I'd find it a bit boring. But they just provide a challenge in different way which I didn’t expect so I'm glad now that I had that opportunity to see because it has affected the schools I would have applied for. But I still have that thing of wanting to work with challenging pupils but I just enjoy more than I would those who are quite intelligent

So, whilst Kelly started her journey towards becoming a teacher expressing a desire to become a particular type of teacher in a particular setting (aligned to her own working-class background), having such a positive placement at a more socially-mixed school, Kelly re-evaluated her stance and liked the challenges a school in an 'other' social/class context brought. After obtaining this post at Daisywood, Kelly was asked to reflect back to her own educational experiences and how they had impacted on her views about teaching, she said: 
Probably a confidence thing. It didn’t make me feel as confident when I started teaching and I didn't think I'd be able to go in a high achieving school and do well. I thought, I didn’t think I'd be able to develop people’s learning but I’ve learned how to do that and I'm quite confident in that now...

Here, Kelly articulates that her own 'classed' education and identity had been very restrictive, particularly on her confidence about choosing the types of schools she thought she could teach in. In this way, Kelly is addressing some of the 'injuries of class' (Sennett and Cobb 1977) she has suffered as a result of being working class (with strong references to feelings of having to 'prove' herself worthy when she had detailed her own experiences of schooling and university). Having had a positive placement in an arguably more middle-class setting, Kelly gained that confidence and with this new confidence, had been opened up to new horizons, those she had initially feared had been too academic for her, the more 'middle-class' settings.

Thus with both Clare and Kelly, whilst their decisions were tied strongly to an initial sense of positivity in that they could empathise and relate to the inner city schools serving working-class communities, there is also a sense that their working-class identities served to inhibit their confidence to consider moving into other contexts. What is inescapable here is the way in which these working-class novice teachers’ intentions had (at least initially) been seemingly bound to their working-class identities in restrictive ways. These were linked to anxieties about their academic abilities and their capacity to cope in non-working class settings with workingclassness associated with notions of inferiority compared to middle-class superiority (Skeggs 1997). It would seem that whilst their ability and empathy towards working with children from 
working-class backgrounds might well be a strength for such novice teachers, it also acted as strategy through which to draw out positive cultural capital from their potentially constraining and restrictive classed identities in the context of teaching. For Kelly, having had that contrasting experience enabled her to re-evaluate her initial stance and thus serves as evidence to be discussed further later in this paper with regard to implications for teacher education.

\section{Strategically 'invisible’ (middle-class) identities}

Both Simon (aged 23) and Matt (aged 29) (who were both white) did not identify as belonging to a social class on their initial questionnaires. When asked to explain why he did not identify as belonging to a social class, Matt said:

Matt: It’s a bit of a mixture because my father's side were working class but my mother's side were very much kind of like, upper class... now my mother inherited all the money off my grandfather and she doesn’t have to work, but she’s a bus driver. She's had plastic surgery done as well. Bus driver and plastic surgery, it baffles me... So that's why I can't class myself as either, or just a bit of both really...

Lisa: so you don’t like to label yourself?

Matt: I don’t tag myself, no. Probably someone else will tag me with something but I don’t know what it will be. I'm not particularly bothered ... No significance to me whatsoever... I don't think anyone's even asked me what class I'm considered from, I wouldn't have a clue, probably middle’ish, maybe working, lower, dunno. 
Here Matt expresses clear ambivalence towards class ('not bothered' and 'no significance whatsoever'). He also discusses the complexity around positioning himself based on his parents differing class backgrounds, though this is not without contradiction as he says his father is from a working-class background when he later says his father's father was a head teacher. It is also interesting to note though that he claims to never have been asked before about his class.

When Simon, who attended a fee-paying boarding school and whose parents had senior civil service roles, was asked about why he did not regard himself as belonging to a social class, he said:

...I'm probably about as middle class as they come. I don’t know, I just felt a bit weird, I don't feel particularly affiliated as social class, but I can see a lot people probably do... I just like, there's load of middle-class kids in Willow [one of his placement schools] and you can probably see the parents fashioning them to be lawyers or whatever it is what you want to be...

Simon then seems acutely aware of class labels but appears to be distancing himself from particular middle-class parenting practices ('fashioning them to be lawyers'). He also discussed how many of his friends from his independent school were 'a little bit too money driven' to go into teaching themselves. Furthermore, Simon also talked of his own sister's desire to operate solely within her (classed) 'comfort zone' and his pride in his willingness to step outside of this into the class 'other': 
...[she's] a bit panicky about the whole urban thing and I think if you put her in any sort of school, or particularly an urban one, she wouldn't feel comfortable. But I'm relatively proud to put myself in those situations...

Whilst it may well be the case that this is an accurate reflection of both Matt and Simon's feelings on class, what is of interest here is the way in which this might be viewed as a strategic non- or dis-identification with class directly linked to the context of becoming a teacher. Moreover, Matt and Simon offer potentially valuable insights into further understanding the way in which entering into teaching involves tensions for novice teachers in relation to their own class identities. In particular, there is a strong sense that their class identity might need to be 'handled' (strategically) to draw out positive cultural capital in situations where they perceive that it might not be as positively valued. This interpretation is potentially very powerful once considered alongside their early intentions in teaching, with Simon identifying very strongly, that he wanted to work in a school and class setting vastly different to his own schooling and identity and with Matt talking about remaining completely neutral and open to context but talking about wanting to work with 'average' children, whom he aligned himself to:

I think that in terms of education, issues that are played out, a lot of the challenging things around socio-economic issues, these are the sort of issues I would like to work with... I feel that I have been what you would say quite privileged in my personal education and I would like to give a bit back as it were... I'm in danger of sounding a bit clichéd but y’know the problems of drug abuse, real poverty, violence, underachievement in education, and it's something I would like to contribute to... (Simon) 
...I was very much an average kid at school and my theory is that the average kids don't get any attention whatsoever. They're average, they're always going to be average, just have average jobs... So my focus is mainly going to be on the average kids... My school was very, well average, it was average, just got on with it, went to school every day just did what I needed to do, did the assignments on time ...I just turned up and did what I needed to do. Didn't really like any of the teachers, didn't really hate any of the teachers it was just pretty boringly average. (Matt)

It would therefore appear that for Simon, becoming a teacher was explicitly about crossing class boundaries. By Simon's own admission, even the act of entering into teaching (and in the state sector) was viewed somewhat as a form of ‘class-crossing’ (Kirk 2004; Maguire 2005) given how he positioned this as outside of his class norms. Furthermore, Simon was also actively choosing to work in the class 'Other' environment, that of a working-class school. In this context, Simon appears aware that his own class identity might create some barriers for him, with Morley’s $(1997,114)$ observation that there are: ‘ ...advantages and disadvantages to being perceived as working class by some and middle class by others...' seemingly pertinent here.

Simon thus appears to consider that in the context of teaching (both the state sector and specifically in an inner city comprehensive), his own 'privileged' classed identity may be seen as a disadvantage and that the cultural capital that he brings may not be highly valued. However, rather than accept this potential limitation and allow his class identity to constrain him, as an 'injury of class’ (Sennett and Cobb 1977) like Clare and Kelly arguably had, Simon engaged in 
what could be viewed as a form of playing with/managing with his own class identity, a process of dis-identification of class (Savage, Silva, and Warde 2010; Reay, Crozier, and James 2011) in order to handle the 'crossing' of the class boundaries he envisaged. Therefore, whilst it may be true that Simon may have genuinely felt no affiliation to his social class background and a set of values he saw (and believed others might see) as underpinning it, he was able to handle his class identity in strategic ways that others in this study, and particularly the working-class novice teachers discussed earlier, did/could not.

Similarly, Matt's attempt to construct himself as 'classless' and 'average' might well be viewed as a strategy to distance himself from his class identity in a context whereby he wanted to remain open to context to enable him to access available opportunities that might be available in the UK teaching jobs market. As both Savage, Bagnall, and Longhurst (2001) and Payne and Grew (2005) note, the choice to use labels such as 'ordinary/normal', or in Matt's case, 'average' in the context of social class, often lose their neutrality because they may seek to render class advantages invisible. In seeking to identify himself as 'average', Matt is not burdened with any imposed class labels and/or perceived levels (or absences) of associated cultural capital. This then leaves him free to choose any teaching context (which he maintained was his intentions from the start of the study) rather than be pushed in constraining ways to particular contexts or having to dis/affiliate from/to any particular classes. Like with Clare and Kelly, there are potentially valuable lessons to be learnt from this for all ITE programmes. 


\section{Implications for initial teacher education and training}

In summary, what the above discussion has demonstrated is that the novice teachers discussed here appeared (whether explicitly or implicitly) to recognise that teaching in many contexts may require them to cross social class boundaries, that is, to go into class contexts different to their own identities and experiences. This in turn forces them to consider how their own class identities need to be negotiated in that process. This paper has therefore demonstrated two broad responses in terms of the novice teachers' anticipation of crossing these boundaries that was demonstrated by all but one of the novice teachers in this study (with only one demonstrating a strong sense of class reflexivity).

The first response to the above dilemma was to avoid crossing these boundaries, setting their sights on a teaching context in a familiar class setting. In the wider study, the restrictive element of one's class identity was certainly not limited to those novice teachers aligned to working-class identities. However, a strong sense of not being 'academic' or 'clever' enough to cross the perceived boundaries to teach 'bright' middle-class children and only being good enough to teach 'low ability’ children was. This conflation of class and ability and the educational 'othering' of working class educational experiences is particularly troubling, especially if left unchallenged and implicitly accepted as part of a 'natural' class hierarchy in which future teachers (from both working and middle-class backgrounds) take this forward into their future classroom practice.

The second response to the perceived boundaries was to attempt to cross them but in doing so, strategies needed to be called upon in terms of constructing an identity that would potentially be 
less troublesome, particularly where it was anticipated that the cultural capital they brought (or would be perceived to bring) might disadvantage them in the context of teaching in particular settings. This latter response highlights the way individuals might seek out strategies to distance themselves from class particularly when they feel threatened (Savage, Bagnall, and Longhurst 2001). What is arguably also pertinent here is the way in which this ability to play more reflexively with one's class and be able to draw on such distancing strategies is itself evidence of a particular form of cultural capital seemingly more able to be utilised by the middle rather than working-class novice teachers in this study (Ball 2003).

What this paper has highlighted is that class identities are potentially troubling territory for all novice teachers, including those from both working and middle-class backgrounds, with a strong sense that for some at least, their classed identities are unfairly constraining and shaping them in ways that might not enable them to make informed choices about their futures in teaching. In addition, some novice teachers who recognise at least some of this, may be being forced to act in covert and strategic ways to handle the potentially constraining nature of their class identities.

This has major implications for ITE. The evidence presented here offers further support for particular approaches developed in the US and Australia, that the specific discussion of the social and cultural backgrounds and identities of new teachers in an open but critical way should be on the agenda for all novice teachers as they learn to teach (Gay 2010; Santoro 2009). In this way, the types of tensions that arise as a result of social class boundary crossing in teaching could be foregrounded and discussed reflexively out in the open in a 'safe' space, especially when issues of social class are directly explored (Jones and Vagle 2013; Van Galen 2010). This would then 
offer assistance to novice teachers that may prevent them being constrained by their class or forced into accepting the only way to avoid these limitations, is to strategise, deny or disassociate with their class identities. It would also benefit all novice teachers in helping them move away from deficit discourses on class that label working-class children as 'less bright' than their middle-class counterparts.

This of course is not without difficulty, particularly in the ITE context in England and other countries that have experienced sustained political interventions to prepare a workforce for a school system driven by neoliberal concerns around 'raising standards' and high-stakes testing (Furlong 2013) with the resulting loss of teacher autonomy and professionalism (MacBeath 2011). In addition, consecutive governments have sought to substantially relocate ITE from universities into more school-led routes (Gilroy 2014) with such imperatives further restricting the already limited space to explore these important issues, especially when the dominant view is that teaching is 'craft' where new teachers will learn all they need to learn by observing expert craftsmen/women (experienced teachers) in practice (Mutton, Burn and Menter 2017). As Maguire (2014, 778) argues, "the assumption being made is that teacher education should be driven by a traditional notion of what counts as a subject and that wider pedagogical concerns of ethics, values and social relations do not need attention". Here, "the teacher is being reconstructed as a state technician, trained by various 'providers' to 'deliver' a national curriculum” (p779), leaving little doubt that problematising class inequalities or the classed identities of novice teachers is likely to be low down on the policymaking agenda. 
However difficult, this paper argues that it is crucially important within critical teacher education concerned with issues of social justice that novice teachers are equipped to be able to work with students from diverse and often different backgrounds to their own. In ignoring social class as a constitutive shaping influence in the early career decisions of novice teachers, including the influence this may have on both emerging values and practices, ITE systems (in whatever format), are leaving this important aspect both unquestioned and unproblematised (LadsonBillings 2001).

The importance of ensuring that ITE offers all novice teachers the opportunity to experience a range of different and contrasting educational experiences as outlined by Ellis et al. (2016) is further highlighted in this paper. We saw how for Kelly, a 'contrasting' placement had the power to challenge and disrupt potential limiting aspects of novice teachers' identities enabling her to question her initial understandings of what type of teacher she wanted to become and in what type of school. This is particularly worrying given the current trend towards school-based ITE programmes that also appear to offer more limiting opportunities for such contrasting placements (Burn and Childs 2016).

As Gay (2010) argues, teachers can only truly begin to tackle educational inequalities and commit to a social justice agenda, equipped with 'equity literacy’ (Gorski 2016, 384) once they understand that education and schooling are far from neutral as with their own identities. In other words, foregrounding the discussion and critique of novice teachers' own class identities in a safe but critically questioning space within ITE might then begin to fully engage with the 
stubborn and persistent patterns of class inequalities more broadly, addressing what Reay (2006,

290) called the 'absent-presence' in teacher education (Grudnoff et al. 2016; Reay 2004).

\section{References}

Allard, A.C. and N. Santoro. 2006. “Troubling Identities: Teacher Education Students' Constructions of Class and Ethnicity”. Cambridge Journal of Education, 36(1): 115-129. doi: 10.1080/03057640500491021.

Ball, S.J. 2003. Class Strategies and the Education Market - The Middle Classes and Social Advantage. London: Routledge Falmer.

Bauman, Z. 1982. Memories of Class. London: Routledge.

Beck, U. 1992. The Risk Society: Towards a New Modernity. London: Sage.

Bennett, T., M. Savage, E. Silva, A. Warde, M. Gayo-Cal and D. Wright. 2009. Culture, Class, Distinction. Abingdon: Routledge

Bottero, W. 2014. “'Class’ in Britain”. In Palgrave Handbook of Sociology in Britain, edited by J. Holmwood and J. Scott, 536-562. Basingstoke: Palgrave Macmillan.

Bourdieu, P. 1986. “The Forms of Capital”. In Handbook of Theory and Research for the Sociology of Education edited by J. Richardson, 241-258. New York: Greenwood Press.

Burn, E. 2001. "Battling Through the System: a Working-Class Teacher in an Inner-City Primary School”. International Journal of Inclusive Education 5(1): 85-92.

doi: 10.1080/13603110010007205.

Burn, K. and A. Childs. 2016. "Responding to Poverty Through Education and Teacher Education Initiatives: a Critical Evaluation of Key Trends in Government Policy in England 1997-2015”. Journal of Education for Teaching: International Research and Pedagogy 42(4): 387-403. doi: 10.1080/02607476.2016.1215547.

Crompton, R. 2008. Class and Stratification 3rd ed. Cambridge: Polity Press.

Devine, F. 1997. Social Class in America and Britain. Edinburgh: Edinburgh University Press.

Dunne, M. and L. Gazeley. 2008. "Teachers, Social Class and Underachievement”.

British Journal of Sociology of Education 29 (5): 451-463. doi: 10.1080/01425690802263627.

Ellis, S., I. Thompson, J. McNicholl and J. Thomson. 2016. "Student Teachers' Perceptions of the Effects of Poverty on Learners' Educational Attainment and Well-Being: Perspectives from England and Scotland”. Journal of Education for Teaching: International Research and Pedagogy 42 (4): 483-499. Doi: 10.1080/02607476.2016.1215542.

Evans, G. 2017. "Social Class and the Cultural Turn: Anthropology, Sociology and the PostIndustrial Politics of 21st Century Britain”. The Sociological Review Monographs 65 (1): 88-104. doi: 10.1177/0081176917693549.

Furlong, J. 2013. "Globalisation, Neoliberalism, and the Reform of Teacher Education in

England.” The Educational Forum 77: 28-50. doi: 10.1080/00131725.2013.739017.

Gay, G. 2010. Culturally Responsive Teaching: Theory, Research and Practice. New York: Teachers College Press.

Gazeley, L. and M. Dunne. 2007. "Researching Class in the Classroom: Addressing the Social Class Attainment Gap in Initial Teacher Education”. Journal of Education for Teaching: International Research and Pedagogy 33(4): 409-424. doi: 10.1080/02607470701603209. 
Gewirtz, S. 2001. "Cloning the Blairs: New Labour's programme for the re-socialization of working-class parents”. Journal of Education Policy 16 (4): 365-378. doi:

10.1080/02680930110054353

Gilroy, P. 2014. "Policy Interventions in Teacher Education: Sharing the English Experience”. Journal of Education for Teaching: International Research and Pedagogy 40(5) 622-633. doi:10.1080/02607476.2014.957996.

Gorski, P. C. 2012. “Teaching against Essentialism and the Culture of Poverty.” In Cultivating Social Justice Teachers: How Teacher Educators Have Helped Students Overcome Cognitive Bottlenecks and Learn Critical Social Justice Concepts, edited by P. Gorski, K. Zenkov, N. Osei-Kofi, and J. Sapp, 84-107. Sterling, VA: Stylus.

Gorski, P.C. 2016. "Poverty and the Ideological Imperative: A Call to Unhook from Deficit and Grit Ideology and to Strive for Structural Ideology in Teacher Education”. Journal of Education for Teaching: International Research and Pedagogy 42 4: 378-386.

doi: 10.1080/02607476.2016.1215546.

Grudnoff, L., M. Haigh, M. Hill, M. Cochran-Smith, F. Ell and L. Ludlow. 2016.

"Rethinking Initial Teacher Education: Preparing Teachers for Schools in Low Socio-Economic Communities in New Zealand”. Journal of Education for Teaching: International Research and Pedagogy 42 (4): 451-467. doi: 10.1080/02607476.2016.1215552.

Hall, D. and L. Jones. 2013. "Social class (in)visibility and the professional experiences of middle-class novice teachers.” Journal of Education for Teaching. 39 (4): 416-428. Doi: 10.1080/02607476.2013.782121.

Hollingworth, S. and Williams, K. 2009. “Constructions of the working-class 'Other' among urban, white, middle-class youth: ‘chavs', subculture and the valuing of education”. Journal of Youth Studies. 12(5): 467-482, doi: 10.1080/13676260903081673

Jones, S. and M. D. Vagle. 2013. "Living Contradictions and Working for Change: Toward a Theory of Social Class-Sensitive Pedagogy.” Educational Researcher 42 (3): 129-141 doi: 10.3102/0013189X13481381

Kirk, J. 2002. “Invisible Ink: Working-Class Writing and the End of Class”. European Journal of Cultural Studies, 5(3), 343-362. doi: 10.1177/1364942002005003070.

Kirk, J. 2004. “Crossing the Border: Class and the Narrative of Transition”. The Minnesota Review, 61-62: 135-147.

Ladson-Billings, G. 2001. Crossing Over to Canaan. The Journey of New Teachers in Diverse Classrooms. San Francisco: Jossey-Bass.

Lash, S. and J. Urry, 1987. The End of Organized Capitalism. Cambridge: Polity Press.

Leathwood, C. and Archer, L. 2006. "Social Class and Educational Inequalities: the local and the global (Editorial)”. Pedagogy, Culture and Society, 12 (1): 5-13. doi: 10.1080/14681360400200186.

MacBeath, J. 2011. "Education of teachers: the English experience”. Journal of Education for Teaching. 37 (4): 377-386. doi:10.1080/02607476.2011.610988

Maguire, M. 2001. “The Cultural Formation of Teachers' Class Consciousness: Teachers in the Inner City”. Journal of Education Policy 16 (4): 315-331. doi: 10.1080/02680930110054326.

Maguire, M. 2005. “Textures of Class in the Context of Schooling: the Perceptions of a 'Class Crossing’ Teacher”. Sociology 39 (3): 427-443. doi: 10.1177/0038038505052492. 
Maguire, M. 2014. "Reforming teacher education in England: 'an economy of discourses of truth'”. Journal of Education Policy, 29 (6): 774-784. doi:

10.1080/02680939.2014.887784

Morley, L. (1997) A Class of One's Own: Women, Social Class and the Academy, In Class Matters: 'Working-Class' Women's Perspectives on Social Class edited by P. Mahony and C. Zmroczek, 109-122. London: Taylor \& Francis Ltd.

Mutton, T., K. Burn and I. Menter. 2017. "Deconstructing the Carter Review: competing conceptions of quality in England's 'school-led' system of initial teacher education”. Journal of Education Policy. 32(1): 14-33. doi: 10.1080/02680939.2016.1214751

Pakulski, J. and M. Waters. 1996. The Death of Class. London: Sage Publications Ltd.

Payne, G. and C. Grew. 2005. “Unpacking 'Class Ambivalence’: Some Conceptual and Methodological Issues in Accessing Class Cultures”. Sociology 39 (5): 893- 910. Doi: 10.1177/0038038505058371.

Reay, D. 2004. “Social Class and Initial Teacher Education”. Paper presented at European Conference on Educational Research, Dublin, September 2004 http://multiverse.ac.uk/attachments/afc1cf08-3a83-4967-802f-121a916901a9.pdf

[Accessed online 27/8/10].

Reay, D. 2006. “The Zombie Stalking English Schools: Social Class and Educational Inequality”. British Journal of Educational Studies 54(3): 288-307. doi: 10.1111/j.14678527.2006.00351.x.

Reay, D. 2017. Miseducation; Inequality, education and the working classes. Bristol: Policy Press.

Reay, D. and H. Lucey. 2004. Stigmatised choices: social class, social exclusion and secondary school markets in the inner city. Pedagogy, Culture and Society 12 (1), 33-51 doi: 10.1080/14681360400200188

Reay, D., G. Crozier and D. James. 2011. White Middle-Class Identities and Urban Schooling. London: Palgrave Macmillan. doi: 10.1057/9780230302501.

Roseneil, S. and S. Frosh, eds. 2012. Social Research After the Cultural Turn. London: Palgrave Macmillan.

Santoro, N. 2009. "Teaching in Culturally Diverse Contexts: What Knowledge About 'Self' and 'Others’ Do Teachers Need?” Journal of Education for Teaching: International Research and Pedagogy 35 (1), 33-45. doi: 10.1080/02607470802587111.

Savage, M. 2003. “Review Article: A New Class Paradigm?” British Journal of Sociology of Education 24 (4): 535-541. doi: 10.1080/014259032000109431.

Savage, M., G. Bagnall and B. Longhurst, B. 2001. "Ordinary, Ambivalent and Defensive: Class Identities in the Northwest of England”. Sociology 35 (4): 875-892.

doi: 10.1177/003803850103500400

Savage, M., N. Cunningham, F. Devine, S. Friedman, D. Laurison, L. Mckenzie, A. Miles, H. Snee and P. Wakeling. 2015. Social Class in the $21^{\text {st }}$ Century. London: Pelican Books.

Savage, M., E. Silva and A. Warde. 2010. Dis-identification and Class Identity. In Cultural Analysis and Bourdieu's Legacy: Settling Accounts and Developing Alternatives, edited by E. Silva and A. Warde, 60-74. London: Routledge.

Sennett, R. and J. Cobb. 1977. The Hidden Injuries of Class. Cambridge: Cambridge University Press.

Skeggs, B. 1997. Formations of Class and Gender. London: Sage. 
Stahl, G. 2015. Identity, Neoliberalism and Aspiration - Educating White Working-Class Boys. Abingdon: Routledge.

Van Galen, J. 2010. “Class, Identity and Teacher Education”. Urban Review 42: 253-270. doi: 10.1007/s11256-009-0136-z.

Vincent, C., N. Rollock, S. Ball and D. Gillborn. 2012. "Being Strategic, Being Watchful, Being Determined: Black Middle-Class Parents and Schooling”. British Journal of Sociology of Education 33 (3): 337-354. doi: 10.1080/01425692.2012.668833. 